\title{
Video Article \\ A Novel Technique for Generating and Observing Chemiluminescence in a Biological Setting
}

\author{
Gabriel E. Büchel ${ }^{1,2}$, Brandon Carney ${ }^{1,3}$, Jun Tang ${ }^{1}$, Brian M. Zeglis ${ }^{1,3}$, Jörg Eppinger ${ }^{2}$, Thomas Reiner ${ }^{1,4}$ \\ ${ }^{1}$ Department of Radiology, Memorial Sloan Kettering Cancer Center \\ ${ }^{2}$ KAUST Catalysis Center, King Abdullah University of Science and Technology \\ ${ }^{3}$ Department of Chemistry, Hunter College, and PhD Program in Chemistry, Graduate Center of City University of New York \\ ${ }^{4}$ Department of Radiology, Weill Cornell Medical College
}

Correspondence to: Thomas Reiner at reinert@mskcc.org

URL: https://www.jove.com/video/54694

DOI: doi:10.3791/54694

Keywords: Bioengineering, Issue 121, Ruthenium, Cerium, Chemiluminescence, Intraoperative imaging, Lymph nodes, in vivo

Date Published: 3/9/2017

Citation: Büchel, G.E., Carney, B., Tang, J., Zeglis, B.M., Eppinger, J., Reiner, T. A Novel Technique for Generating and Observing Chemiluminescence in a Biological Setting. J. Vis. Exp. (121), e54694, doi:10.3791/54694 (2017).

\section{Abstract}

Intraoperative imaging techniques have the potential to make surgical interventions safer and more effective; for these reasons, such techniques are quickly moving into the operating room. Here, we present a new approach that utilizes a technique not yet explored for intraoperative imaging: chemiluminescent imaging. This method employs a ruthenium-based chemiluminescent reporter along with a custom-built nebulizing system to produce ex vivo or in vivo images with high signal-to-noise ratios. The ruthenium-based reporter produces light following exposure to an aqueous oxidizing solution and re-reduction within the surrounding tissue. This method has allowed us to detect reporter concentrations as low as $6.9 \mathrm{pmol} / \mathrm{cm}^{2}$. In this work, we present a visual guide to our proof-of-concept in vivo studies involving subdermal and intravenous injections in mice. The results suggest that this technology is a promising candidate for further preclinical research and might ultimately become a useful tool in the operating room.

\section{Video Link}

The video component of this article can be found at https://www.jove.com/video/54694/

\section{Introduction}

In recent decades, imaging technologies have revolutionized the way that physicians diagnose and monitor disease. These imaging technologies, however, have been largely limited to whole body imaging systems, such as positron emission tomography (PET), single photonemission computed tomography (SPECT), computed tomography (CT), and magnetic resonance imaging (MRI). Particular attention has been paid to cancer, and technological imaging breakthroughs have greatly improved the way that this disease is diagnosed and treated. Despite these advances, there is one place where these imaging technologies just don't fit: the operating room. While whole body imaging techniques can help in surgical planning, they typically lack spatial resolutions high enough to help physicians determine in real-time whether all of the tumor tissue has been removed or residual tumor tissue remains hidden at the surgical margins ${ }^{1}$. Making sure that no infiltrative tumor margins are left behind is one of the most important surgical goals, and surgeons must walk a tight-rope between rigorous and cautious tissue resection. If too much is removed, unwanted side effects for the patient are exacerbated; if too little is removed, recurrence rates are increased ${ }^{2,3}$. Therefore, it is crucial to delineate accurate tumor margins, and we believe that chemiluminescent intraoperative imaging can help to improve the accuracy of the identification of tumor margins by helping surgeons to visualize malignant tissue that could otherwise remain undetected with established techniques.

There are many imaging technologies currently being investigated for their possible utility as intraoperative imaging systems. These include $\beta$ and $y$-radiation-emitting probes ${ }^{4}$, optical fluorescence ${ }^{5}$, Raman spectroscopy ${ }^{6,7}$, and Cherenkov luminescence ${ }^{8,9}$. To date, however, none of these have become established as standard clinical tools. Optical fluorescence imaging has so far proven to be the most promising of these techniques and is therefore the most explored. While it has already been shown to be a valuable tool for many applications, it is not without its limitations. Indeed, its principal drawback is the background fluorescence generated by inherently autofluorescent biological tissue. This background autofluorescent signal is a product of the excitation of the surrounding tissue, in addition to the fluorophore, by the external light source needed for the generation of a fluorescent signal. From a practical perspective, this autofluorescence can potentially lead to low signal-tonoise ratios, which can limit the utility of this technology in the operating room.

The principal advantage of chemiluminescence imaging over fluorescence imaging is that no excitation light is necessary. As a result, there is no background autofluorescence. In chemiluminescence imaging, the excitation energy is instead generated chemically. This process produces no unintended background signal and therefore can result in higher signal-to-noise ratios. This could ultimately result in the more precise and accurate detection of surgical margins. Somewhat surprisingly, the utility of this approach as an intraoperative imaging technique has remained unexplored $^{10}$. Indeed, the closest example to this technique is the oxidation of luminol by myeloperoxidase in mice ${ }^{11,12,13}$. Chemiluminescent 
biomedical imaging is therefore a rather unexplored area of research that could offer the following advantages: (1) minimal autofluorescence resulting in a low background signal with higher signal-to-noise ratios; (2) tunable wavelengths of chemiluminescent emissions ranging from the visible to the near-infrared; and (3) functionalizable chemiluminescent complexes that, when combined with linker technologies and targeted biomolecules that already exist, provide access to whole libraries of targeted molecular imaging probes ${ }^{14}$.

This proof-of-principle study illustrates the potential utility of chemiluminescent imaging in the biomedical setting using a ruthenium-based imaging agent. The chemiluminescent properties of this compound are well studied, with investigations dating back to the mid-1960s ${ }^{15}$. Upon chemical activation, the agent produces light at around $600 \mathrm{~nm}^{16}$, which is well suited for medical imaging purposes. The activation energy is provided by a redox reaction that leads to an excited state-which has a lifetime of $650 \mathrm{~ns}$ in water ${ }^{17}$-followed by the generation of photons upon relaxation of this excited state. Through the use of a specially-designed remote nebulizer, we were able to detect the compound both ex vivo and in vivo. The results of initial experiments are very promising, suggesting further investigation of this technology.

\section{Protocol}

Ethics statement: All of the in vivo animal experiments described were performed according to an approved protocol and under the ethical guidelines of the Memorial Sloan Kettering Cancer Center (MSK) Institutional Animal Care and Use Committee (IACUC).

\section{Construction of a Nebulizing Device}

1. Attach wood part $A\left(12.5 \times 2.5 \times 1.8 \mathrm{~cm}^{3}\right)$ upright in the center of part $B\left(12.7 \times 10.7 \times 1.8 \mathrm{~cm}^{3}\right)$ using two screws $\left(4 \times 25 \mathrm{~mm}{ }^{2}\right)$. Attach wood part $C\left(11 \times 2.5 \times 1.8 \mathrm{~cm}^{3}\right)$ to the middle of part $A\left(12.5 \times 2.5 \times 1.8 \mathrm{~cm}^{3}\right)$ using one screw, such that part $C\left(11 \times 2.5 \times 1.8 \mathrm{~cm}^{3}\right)$ can still be moved. See Figure 1.

2. Drill two holes through the lower tip of the spray bottle trigger of a plastic $3 \mathrm{oz}$ mini sprayer (D) and push a stainless steel rod (10 $\mathrm{cm}$ of $1 / 16 "$ steel) (E) through to form two loops, one on either side of the trigger.

3. Wrap the bottom part of the spray bottle with duct tape $(F)$ to prevent the cable ties from slipping off. Attach the spray bottle to wood part $C$ $\left(11 \times 2.5 \times 1.8 \mathrm{~cm}^{3}\right)$ using the two plastic cable ties $(28 \mathrm{~cm})(\mathrm{G})$.

4. Cut off the 011 servo motor $(\mathrm{I})$ and reconnect it with the loose cables of the servo control $(\mathrm{H})$. Then, attach the servo motor to the top of wood part $A\left(12.5 \times 2.5 \times 1.8 \mathrm{~cm}^{3}\right)$ using duct tape.

5. Attach a pencil $(\mathrm{J})$ to the servo motor lever using the paper clip $(\mathrm{K})$. Tightly connect the outermost parts of the pencil to the steel rod loops using plastic covered twist wires $(L)$ and secure the ends on the pencil with duct tape.

6. Cut off the servo motor control unit's magnetic cable connector $(\mathrm{M})$ and reattach it to the speaker cable (N). Then, tape the servo motor control unit to wood part $B\left(12.7 \times 10.7 \times 1.8 \mathrm{~cm}^{3}\right)$. Cut a w1 cable with magnetic connectors in half and attach one part to the loose end of the copper speaker cable $(1 \mathrm{~m})$. Connect the (magnetic) i2 toggle switch and p1 power to the available w1 cable and a $9 \mathrm{~V}$ battery.

\section{Sensitivity Determination of the Method}

1. In a $1.5 \mathrm{~mL}$ microcentrifuge tube, prepare solutions of $\left[\mathrm{Ru}(\mathrm{bpy})_{3}\right] \mathrm{Cl}_{2}$ in reverse osmosis water $(100 \mu \mathrm{L})$ in amounts of $260 \mu \mathrm{g}(347 \mathrm{nmol}), 52$ $\mu \mathrm{g}(69 \mathrm{nmol}), 26 \mu \mathrm{g}(34 \mathrm{nmol}), 5 \mu \mathrm{g}(6.9 \mathrm{nmol}), 3 \mu \mathrm{g}(3.5 \mathrm{nmol}), 520 \mathrm{ng}(694 \mathrm{pmol}), 260 \mathrm{ng}(347 \mathrm{pmol}), 52 \mathrm{ng}(69 \mathrm{pmol}), 26 \mathrm{ng}(34 \mathrm{pmol}), 5$ $\mathrm{ng}(6.9 \mathrm{pmol})$, and $3 \mathrm{ng}(3.5 \mathrm{pmol})$.

2. Mix $100 \mu \mathrm{L}$ of each $\left[\mathrm{Ru}(\mathrm{bpy})_{3}\right] \mathrm{Cl}_{2}$ solution with $100 \mu \mathrm{L}$ of an aqueous solution of ammonium cerium nitrate $\left(\left(\mathrm{NH}_{4}\right)_{2} \mathrm{Ce}\left(\mathrm{NO}_{3}\right)_{6}\right)$ in water $(25 \mathrm{mM})$ on a microscope slide.

3. Set up the acquisition in the bioluminescence reader by initializing the imaging software.

1. Sign in to the user profile and look for the acquisition control panel. Click on "Initialize" and wait until the instrument is ready.

2. Look for "Imaging Mode" and make sure "Luminescent" and "Photograph" are checked and that "Fluorescent" is unchecked.

3. Change "Exposure Time" setting for "Luminescent" to $20 \mathrm{~s}$. Set the remaining settings for "Luminescent" as follows: "Binning": Medium; "F/stop": 1; and "Emission Filter": Open.

NOTE: The exposure times might need to be adapted according to the instrumentation and experimental setting used, if different from the presented setup.

4. For "Photograph," use the following settings: "Exposure Time": Auto; "Binning": Medium; and "F/stop": 8. Adjust the "Subject Height" according to imaging target.Look for the "Field of View" dropdown menu. The initial setting is "C." Change to "B" (14 cm distance between the camera and sample stage).

4. Set up the nebulizer by placing a microscopic slide on a sheet of black construction paper on the floor of the imaging chamber to protect it from the oxidizing agent. Mix a $100 \mu \mathrm{Ldroplet}$ of $\left[\mathrm{Ru}(\mathrm{bpy})_{3}\right] \mathrm{Cl}_{2}$-solution with $100 \mu \mathrm{L}$ of an aqueous solution of $\left(\mathrm{NH}_{4}\right)_{2} \mathrm{Ce}\left(\mathrm{NO}_{3}\right)_{6}$. Observe the green box crosshair.

1. Place the imaging subject on the black construction paper, such that the area of interest is in the center of the green light box crosshair displayed on the sample stage. Prepare the nebulizer by detaching the plastic spray bottle from the wooden support. Fill a solution of triethylamine (1:3 in water/ethanol) into its plastic reservoir and reattach it to the wooden support.

2. Place the nebulizer inside the bioluminescence reader and make sure that the power cord is disconnected from the nebulizer cord. Ensure that the power switch is on, the toggle switch is off, and the red LED is lit. Place the nebulizer such that the spray flow is pointed towards the area of interest on the imaging subject, while minimizing the view obstruction from the camera towards the imaging subject by the spray nozzle head.

3. Place small, black pieces of construction paper over any potential hot spots (e.g., white marks on microscopic slides or injection sites) to shield them from spray. Place at least $40 \mathrm{~cm}$ of the nebulizer remote cord inside the imaging chamber, such that it does not interfere with the imaging subject, the nebulizer, or the magnetic door latch. Close the imaging system door.

NOTE: The crosshair will change size based on the "Field of View" setting in "Living Image;" make sure that this is set to "B". 
5. Acquire an image by initiating the imaging sequence. Click "Acquire" in the "Acquisition Control Panel." On the first imaging sequence, enable autosaving if desired (recommended) and choose a data folder. Ignore the "Edit Imaging Labels" dialog until the end of the sequence. NOTE: The control software displays the instrument's actions step-by-step in real time. After preparing the measurement and moving the sample stage to the right position, it opens the camera shutter and counts the measurement time. The shutter opening can also be heard by a click sound generated by the machine.

6. As the shutter opens, spray three bursts of a solution of triethylamine $(1: 3$ in water/ethanol, $0.24 \pm 0.04 \mathrm{~mL}$ per spray burst) by switching the toggle switch three times to generate chemiluminescence.

NOTE: The sample stage will move during the measurement. Leave enough (minimum $40 \mathrm{~cm}$ ) cable inside the instrument to allow this. Make sure that the solution to be sprayed by the nebulizer can be aspired by the ascending pipe and that there are no air bubbles in the pipe. Have several spare batteries for the nebulizer ready in case needed.

\section{In Vivo Imaging After Systemic Intravenous Injection}

1. In a $1.5 \mathrm{~mL}$ microcentrifuge tube, prepare $100 \mu \mathrm{L}$ of phosphate-buffered saline (PBS) solution containing between 8 and $33 \mathrm{nmol}$ of $\left[\mathrm{Ru}(\mathrm{bpy})_{3}\right] \mathrm{Cl}_{2}$. Prepare an aqueous solution of $\left(\mathrm{NH}_{4}\right)_{2} \mathrm{Ce}\left(\mathrm{NO}_{3}\right)_{6}$ in water $(25 \mathrm{mM})$ at the same time.

2. Intravenously inject $100 \mu \mathrm{L}$ of $\left[\mathrm{Ru}(\mathrm{bpy})_{3}\right] \mathrm{Cl}_{2}$ into the tail vein of healthy mice $(\mathrm{n}=5)$.

3. Euthanize the mice $\mathbf{1 0}$ min after injection via $\mathrm{CO}_{2}$ asphyxiation.

1. Remove the skin with a Y-cut from the torso, then remove the costal arch in a U-shape to expose the heart and lungs. Perfuse the mice by cutting an outlet in the right atrium and injecting $20 \mathrm{~mL}$ of PBS through a 24 gauge needle into the left ventricle ${ }^{18}$. Carefully cut through the belly skin and expose the kidney and liver. Cut longitudinally through the organs to create a visible cut.

4. Set up the acquisition as described in steps 2.3-2.6, with the following changes.

1. After thoroughly washing the nebulizer plastic reservoir, fill it with a solution of $\left(\mathrm{NH}_{4}\right)_{2} \mathrm{Ce}\left(\mathrm{NO}_{3}\right)_{6}$ in water $(25 \mathrm{mM})$ instead of triethylamine.

NOTE: It is important to thoroughly rinse the nebulizer nozzle after every use, since crystallizing $\left(\mathrm{NH}_{4}\right)_{2} \mathrm{Ce}\left(\mathrm{NO}_{3}\right)_{6}$ may destroy the spray nozzle after several uses.

5. Use the whole animal or organ samples for imaging.

1. For whole abdomen imaging, position the mouse carcass with the open abdomen facing the camera and the head pointing to the back of the instrument. Center the organ to be imaged (e.g., liver or kidney) in the green light box crosshair.

2. For individual organ imaging and quantification, remove the mouse from the imaging instrument and pin it down. Starting from the already-opened body cavity, excise the inner organs (e.g., kidney, liver, lung, muscle, spleen, brain, and heart). Cut through the hind leg skin to excise muscle tissue. Carefully open the skull with a scalpel to excise the brain.

1. If the organ of interest is liver, kidney or spleen, cut all organs in half longitudinally, place each organ on a petri dish or piece of black construction paper.

3. Follow the procedure described in steps 2.3-2.6 to establish the relative emission of the chemiluminescent tracer for single organs.

\section{In Vivo Imaging of Lymph Nodes}

1. Prepare $10 \mu \mathrm{L}$ of a PBS solution containing $80 \mathrm{nmol}$ of $\left[\mathrm{Ru}(\mathrm{bpy})_{3}\right] \mathrm{Cl}_{2}$. Prepare an aqueous solution of $\left(\mathrm{NH}_{4}\right)_{2} \mathrm{Ce}\left(\mathrm{NO}_{3}\right)_{6}$ in water $(25 \mathrm{mM})$ at the same time.

2. Inject $10 \mu \mathrm{L}$ of the solution subdermally into the hind paw of healthy mice $(n=5)$. As a negative control, inject the contralateral paw with 10 $\mu \mathrm{L}$ of pure PBS. Sacrifice the mice via $\mathrm{CO}_{2}$ asphyxiation $15 \mathrm{~min}$ after the injection. Remove the skin on both hind legs to expose the lymph canals up to the popliteal lymph nodes.

3. Set up the acquisition as described in step 3.4.

4. Remove the popliteal lymph nodes from both hind legs, cut them in half, and spray them with oxidant on a Petri dish, as described before (step 3.5.3), for the purpose of quantification.

\section{Representative Results}

The nebulizer system described in protocol section 1 can be constructed from easily-available materials at a low cost. It is intended to be an inset for remote-triggered spraying of the reducing/oxidizing agent inside a bioluminescent reader (Figure 1). Our design allows for the safe operation of the nebulizer within the bioluminescence reader at a $14 \mathrm{~cm}$ distance from the lens. No fogging or blurring of the lens was observed during the operation. We selected the commercially-available chemiluminescent agent $\left[\mathrm{Ru}(\mathrm{bpy})_{3}\right] \mathrm{Cl}_{2}$ for the development of our method based on its low price, stability in aqueous solution, well-described redox behavior, and chemiluminescent properties (Figure 2$)^{19}$. The minimal detectable signal can be determined as described in protocol section 2 by oxidizing one drop of $\left[\mathrm{Ru}(\mathrm{bpy})_{3}\right] \mathrm{Cl}_{2}\left(100 \mu \mathrm{L}, 6.9 \mathrm{pmol}-347 \mathrm{nmol}\right.$ in $\left.\mathrm{H}_{2} \mathrm{O}\right)$ with $\left(\mathrm{NH}_{4}\right)_{2} \mathrm{Ce}\left(\mathrm{NO}_{3}\right)_{6}(100 \mu \mathrm{L}, 25 \mathrm{mM})$ on a microscope slide. Then, by using the nebulizer and spraying on a solution of triethylamine $(1: 3$ in water/ ethanol), the chemiluminescent signal is triggered. In our case, the minimal detectable signal was determined to be $6.9 \mathrm{pmol} / \mathrm{cm}^{2}(\mathrm{Figure} 3)$. It is conceivable, though, that optimized reaction conditions, camera sensitivities, shutter times, volumes, and reagent concentrations might lead to even lower detection thresholds. These reaction conditions can also be used for exploring and testing the chemiluminescence of any given combination of metal complexes, oxidizing agents, and reductants. 
Moving to the in vivo experiments in protocol sections 3 and 4, female nude (outbred) mice 5-6 weeks old and NU/J male mice 6-8 weeks old were used. For intravenous injections, amounts of $8-33 \mathrm{nmol}$ of $\left[\mathrm{Ru}(\mathrm{bpy})_{3}\right] \mathrm{Cl}_{2}$ in $100 \mu \mathrm{L}$ of PBS per mouse $(\mathrm{n}=5)$ were chosen. The animals were sacrificed $10 \mathrm{~min}$ after injection, and the abdominal cavity was exposed. The mice were placed in the bioluminescent reader with the nebulizer pointing towards the tissue of interest (Figure 4). For imaging with intravenously-injected $\left[\mathrm{Ru}(\mathrm{bpy})_{3}\right] \mathrm{Cl}_{2}$, the chemiluminescent signal was detected predominantly in the kidneys, strongly suggesting renal elimination of the hydrophilic small molecule (Figure 5). Signal-to-noise ratios for mice injected with $\left[\mathrm{Ru}(\mathrm{bpy})_{3}\right] \mathrm{Cl}_{2}$ versus PBS were $27 / 1$ for the kidney and $21 / 1$ for the liver. For lymph node imaging, $80 \mathrm{nmol}$ of $\left[\mathrm{Ru}(\mathrm{bpy})_{3}\right] \mathrm{Cl}_{2}$ in $10 \mu \mathrm{L}$ of PBS were injected subdermally into the hind foot pad of mice $(n=5)$. Mice were sacrificed 15 min post injection by $\mathrm{CO}_{2}$ asphyxiation. The skin covering both the inner hind legs was removed to expose the muscle, lymph nodes, and lymphatic vessels. Subsequent chemiluminescent visualization of the popliteal lymph nodes led to the observation that lymph nodes containing $[R u(b p y)]_{3}{ }^{2+}$ show a $10 \pm 4.3-$ fold higher radiance than untreated ones $\left(167,000 \mathrm{p} /\left(\mathrm{s} \times \mathrm{cm}^{2} \times \mathrm{sr}\right)\right.$ and $\left.17,000 \mathrm{p} /\left(\mathrm{s} \times \mathrm{cm}^{2} \times \mathrm{sr}\right) ; \mathrm{P}<0.028\right)$ (Figure 6).

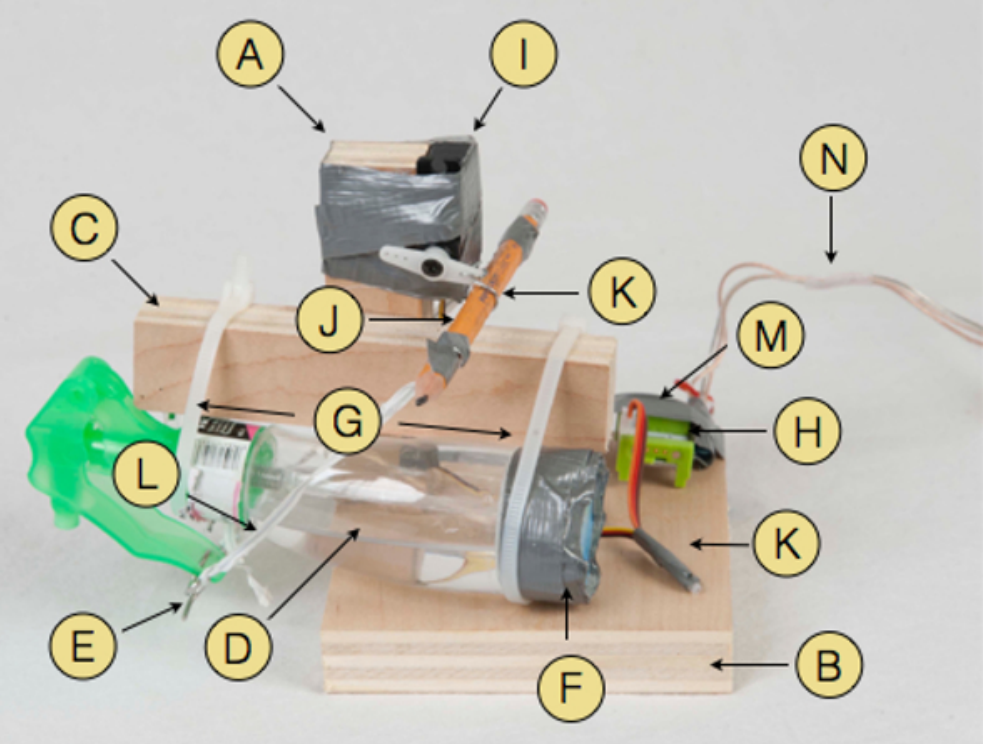

Figure 1: Photograph of the Nebulizer. Parts used: Wooden structure parts $(A, B, C)$, spray bottle $(D)$, bent steel rod $(E)$, duct tape $(F)$, plastic cable ties $(\mathrm{G})$, 011 servo connector part $(\mathrm{H})$, servo motor $(\mathrm{I})$, pencil $(\mathrm{J})$ held by bent paper clip $(\mathrm{K})$, plastic covered wire twist ties $(\mathrm{L})$ w1 wire connector $(\mathrm{M})$ and speaker cable $(\mathrm{N})$ leading to the battery. This figure is based on research originally published in reference ${ }^{19}$. Please click here to view a larger version of this figure.

A<smiles></smiles>

B

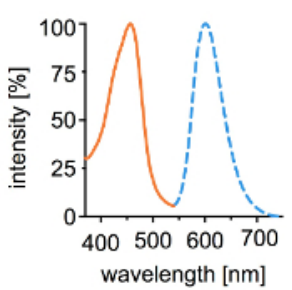

C

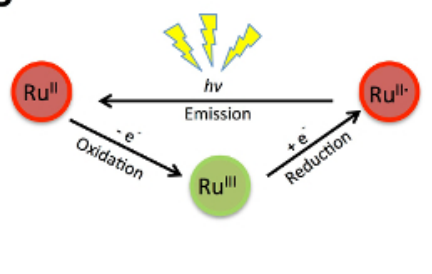

Figure 2. Properties of $\left[R u(b p y)_{3}\right]^{2+}$. Structure $(\mathbf{A})$ and excitation and emission spectra $(\mathbf{B})$ of $\left[\operatorname{Ru}(\mathrm{bpy})_{3}\right]^{2+}$. The oxidation/reduction based chemiluminescent catalytic cycle (C). This figure is based on research originally published in reference ${ }^{19}$. Please click here to view a larger version of this figure.
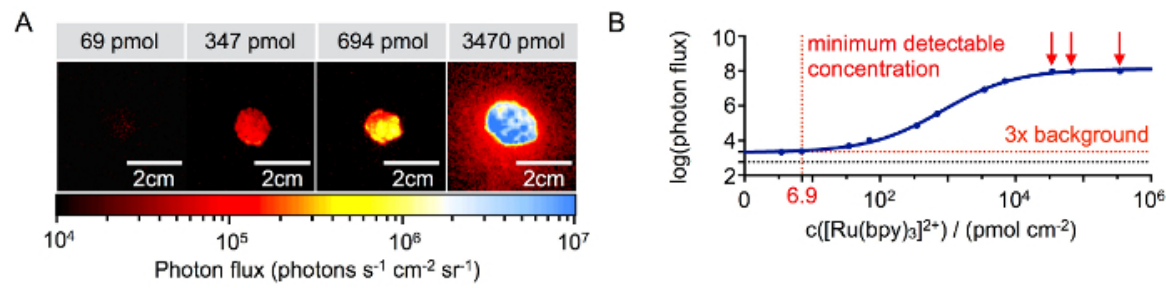

Figure 3: Detection Threshold of $\left[R u(b p y)_{3}\right]^{2+}$. Representative signal intensities at different concentrations of $\left[R u(b p y)_{3}\right]^{2+}$ on a microscope slide (A). Imaging signal quantification with detection threshold (red dotted line) and background (black dotted line) (B). This figure is based on research originally published in reference ${ }^{19}$. Please click here to view a larger version of this figure. 
A

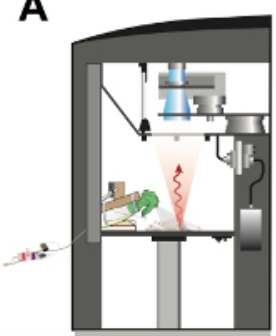

B

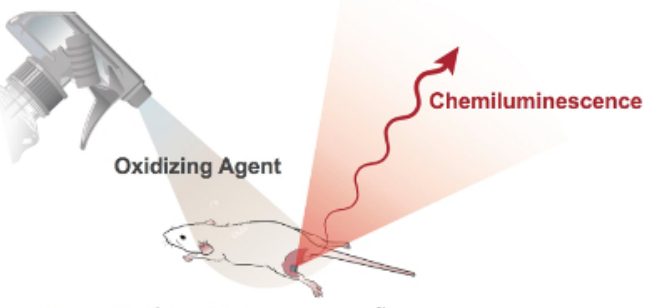

No optical excitation, no autofluorescence

Figure 4: Chemiluminescence Imaging. Schematic drawing of a mouse and a nebulizer positioned in the bioluminescence reader (A) and schematic drawing (B) of the nebulizer spraying on a mouse. This figure is based on research originally published in reference ${ }^{19}$. Please click here to view a larger version of this figure.

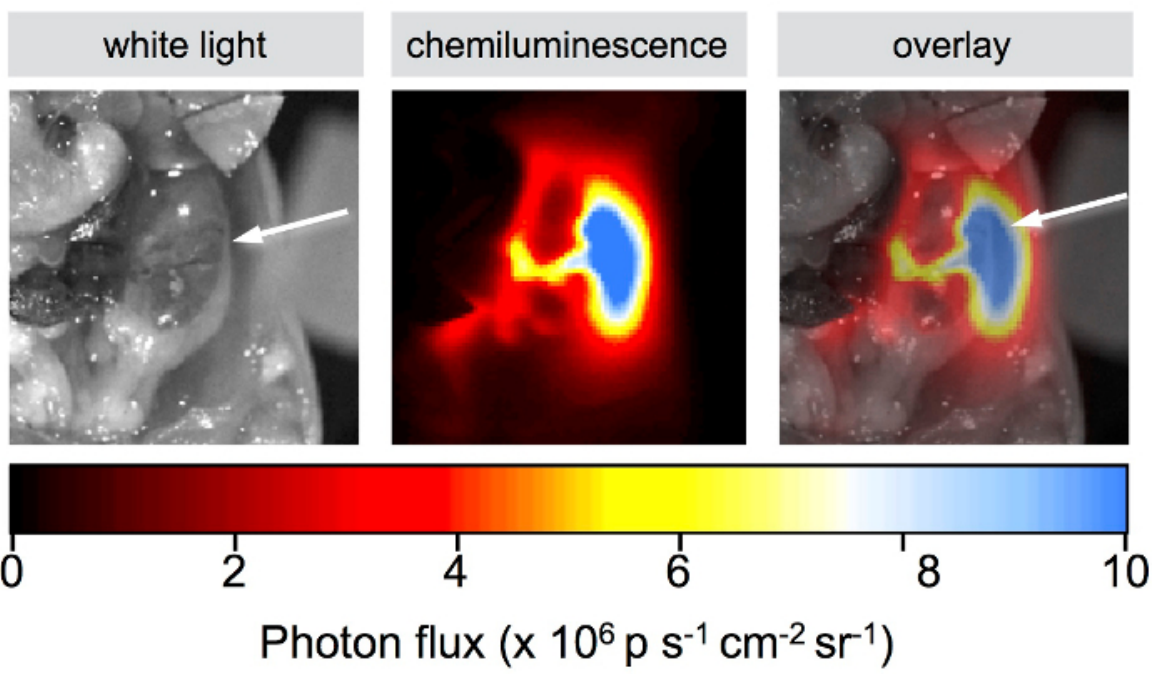

Figure 5: Detection of $\left[\mathrm{Ru}(\mathrm{bpy})_{3}\right]^{2+}$ after Systemic Administration. White light, chemiluminescence, and overlay (from left to right). Images of a mouse body cavity that was injected with $33 \mathrm{nmol}$ of $\left[\mathrm{Ru}(\mathrm{bpy})_{3}\right]^{2+}$ and sprayed with $\left(\mathrm{NH}_{4}\right)_{2} \mathrm{Ce}\left(\mathrm{NO}_{3}\right)_{6}$. The white arrow points towards the right kidney. This figure is based on research originally published in reference ${ }^{19}$. Please click here to view a larger version of this figure.

A

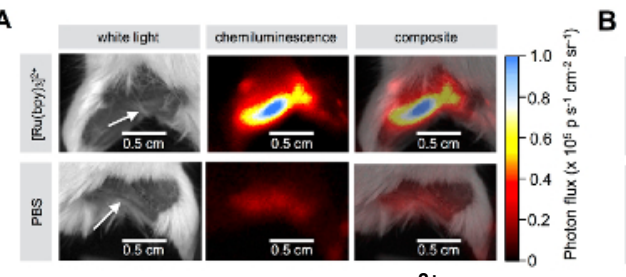

B

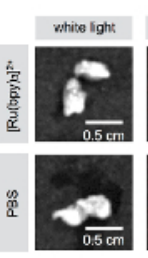

C

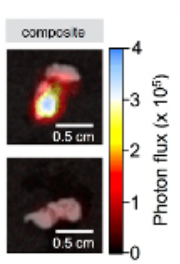

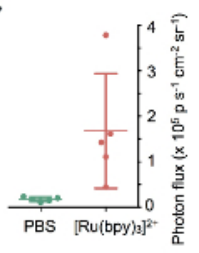

Figure 6: Detection of $\left[\mathrm{Ru}(\mathrm{bpy})_{3}\right]^{2+}$ after Subdermal Administration. Popliteal lymph node imaging showing white light, chemiluminescence, and composite pictures for mice injected with $\left[\mathrm{Ru}(\mathrm{bpy})_{3}\right]^{2+}$ (top) and PBS (bottom) in the hind limbs; $80 \mathrm{nmol}$ in $10 \mu \mathrm{L}$ of PBS, imaged 15 min after injection (A). White light and composite images for $\left[\mathrm{Ru}(\mathrm{bpy})_{3}\right]^{2+}$ (top) and PBS (bottom)-treated excised popliteal lymph nodes (B). Quantification of chemiluminescent signals for PBS and $\left[\mathrm{Ru}(\mathrm{bpy})_{3}\right]^{2+}$-treated lymph nodes $(\mathbf{C})$. The data represents the mean $\pm \mathrm{SD}$. This figure is based on research originally published inreference ${ }^{19}$. Please click here to view a larger version of this figure.

\section{Discussion}

Here, we have presented a technology that is capable of optically delineating tissue via the emission of photons created by a chemiluminescent reporter. In contrast to other, more established, technologies ${ }^{4,5,6,7,8,9}$, this chemiluminescent reporter system employs an imaging probe that is non-radioactive and facilitates detection at very high sensitivity levels. Perhaps even more importantly, chemiluminescence imaging does not require an incident light source (as in optical fluorescence imaging) ${ }^{20}$, a trait that minimizes autofluorescence and drastically reduces background signals.

The ruthenium reporter $\left[\mathrm{Ru}(\mathrm{bpy})_{3}\right] \mathrm{Cl}_{2}$ has an in vivo toxicity tolerable for imaging purposes (intraperitoneal mouse $\mathrm{LD}_{50}: 20 \mathrm{mg} / \mathrm{kg}$ ) ${ }^{21}$, is water soluble (up to $8 \mathrm{mM}$ ), and is stable in the bloodstream. The physicochemical properties of the metal complex are well-characterized and have already been investigated for the photodynamic therapy of cancer ${ }^{22,23}$. The oxidizing agent $\left(\mathrm{NH}_{4}\right)_{2} \mathrm{Ce}\left(\mathrm{NO}_{3}\right)_{6}$ has been reported to have very low toxicity (oral rat $L D_{50}: 1600-3200 \mathrm{mg} / \mathrm{kg}$ ) ${ }^{24}$ and is soluble in water at concentrations of up to $2.57 \mathrm{M}$ at $20^{\circ} \mathrm{C}^{25}$. In this article, a visual demonstration as well as text-based guidance for the construction of a remotely-operated nebulizing device are presented. In addition, we 
provide robust protocols for performing chemiluminescence imaging in a standard bioluminescence imaging device. We illustrate the use of $\left[\mathrm{Ru}(\mathrm{bpy})_{3}\right] \mathrm{Cl}_{2}$ for the visualization of tissues after both intravenous and subdermal injections in mice.

However, as with any other nascent imaging technology, there is room for improvement of our protocols. We believe that this proof-of-principle study could spur the development of multiple chemiluminescence applications for living systems. The following points could be addressed to further improve the technology and expand its scope.

A smaller second generation of remotely triggered spraying devices would allow the sample to be closer to the camera, hence improving spatial resolution. Improved optical equipment might further improve the detection limits of the method. The protocol could also be extended to imaging live animals. Exact control of the torque (by current and voltage) would allow a more exact control of the volume of reagent released with each spray. It is important to keep the nebulizer well-maintained. Not rinsing the nebulizer may destroy the nozzle. A fresh battery is crucial for the proper performance of the nebulizer. However, all the materials used for the nebulizer are inexpensive and readily commercially available. Following established synthetic protocols, the $\left[\mathrm{Ru}(\mathrm{bpy})_{3}\right]^{2+}$ complex can easily be modified with various linkers, including maleimides ${ }^{26}$, amines ${ }^{27}$ and NHS esters ${ }^{28,29}$. This would enable bioconjugation to small molecules, peptides, or antibodies, and would thus facilitate specific molecular targeting ${ }^{30,31,32,33}$. Ultimately, targeted probe delivery could enable surgeons to identify small lesions and to accurately delineate surgical margins in the operating room with very high specificity. Also, the encapsulation of the highly water-soluble $\left[\mathrm{Ru}(\mathrm{bpy})_{3}\right]^{2+}$ in nanomaterials-both targeted and untargeted-may also allow for the visualization of lesions while they are being surgically removed ${ }^{34,35,36}$. Finally, modifying the coordination sphere of the metal complex reporter and/or changing the transition metal center itself represent attractive routes to modulate and fine-tune the emission wavelengths within the visible and NIR ranges ${ }^{37,38}$.

Intraoperative chemiluminescence imaging needs a chemiluminescent reporter and, in our case, an oxidant, which can only be used within the limits of their toxicity and solubility. Tissue membranes can represent a barrier for the diffusion of the oxidant into the tissue, and hence, the signal generation. Since the chemiluminescent reporter is only generating one photon per cycle, the generated signal is rather weak. The ambient light in the operating room will therefore have to be prevented from entering the camera while the technique is in use. This might render $\mathrm{ICI}$ particularly interesting for the development of laparoscopic applications, where ambient light is naturally excluded.

We hope that this method may turn into a valuable tool for surgeons in the operating room. The absence of radioactivity is beneficial to the patient and operating team alike and makes fewer safety precautions necessary, potentially rendering this technique into a more attractive alternative.

The smooth operation of the nebulizer and its positioning play a crucial role for obtaining good results. Suboptimal angles and areas may contribute to signal variance. The control cable must be put through the door with care, and enough cable has to remain inside the bioluminescence reader so that it is not cramped or torn off.

Ultimately, chemiluminescence imaging is an extremely attractive new approach to molecular imaging. It is based on a foundation of wellestablished chemistry, employs inexpensive and readily available materials, and eschews both radiation and excitation light sources. As a result, we are both hopeful and confident that in the future, chemiluminescence imaging could have a profound effect on the surgical treatment of disease.

\section{Disclosures}

The authors have nothing to disclose.

\section{Acknowledgements}

The authors thank Prof. Jan Grimm and Mr. Travis Shaffer for their helpful discussions and Mr. David Gregory for editing the manuscript. Technical services provided by the MSK Animal Imaging Core Facility, supported in part by NIH Cancer Center Support Grant P30CA008748-48, are gratefully acknowledged. The authors thank the NIH (K25 EB016673 and R21 CA191679, T.R. and 4R00CA178205-02, B.M.Z.), the MSK Center for Molecular Imaging and Nanotechnology (T.R.), the Tow Foundation (B.C.), and the National Science Foundation Integrative Graduate Education and Research Traineeship (IGERT 0965983 at Hunter College for B.C. and T.M.S.) for their generous support. The research reported in this publication was supported by funding from the King Abdullah University of Science and Technology.

\section{References}

1. Fong, Y., Giulianotti, P. C., Lewis, J., Koerkamp, B. G., Reiner, T. Imaging and Visualization in The Modern Operating Room: $A$ Comprehensive Guide for Physicians. Springer (2015).

2. Nguyen, Q. T., Tsien, R. Y. Fluorescence-guided surgery with live molecular navigation - a new cutting edge. Nat. Rev. Cancer. 13(9), 653-662 (2013).

3. Weissleder, R., Pittet, M. J. ImRoullinaging in the era of molecular oncology. Nature. 452, 580-589 (2008).

4. Heller, S., Zanzonico, P. Nuclear probes and intraoperative gamma cameras. Semin. Nucl. Med. 41.(3), 166-181 (2011).

5. Dam, G. M. et al. Intraoperative tumor-specific fluorescence imaging in ovarian cancer by folate receptor- $\alpha$ targeting: first in-human results. Nat. Med., 17(10), 1315-1319 (2011).

6. Zavaleta, C. L. et al. A Raman-based endoscopic strategy for multiplexed molecular imaging. Proc. Natl. Acad. Sci. U S A. 110(25), E2288E2297 (2013).

7. Harmsen, S., Bedics, M. A., Wall, M. A., Huang, R., Detty, M. R., Kircher, M. F. Rational design of a chalcogenopyrylium-based surfaceenhanced resonance Raman scattering nanoprobe with attomolar sensitivity. Nat. Commun., 6, 1-9 (2015).

8. Thorek, D. L. et al. J. Positron Lymphography: Multimodal, High-Resolution, Dynamic Mapping and Resection of Lymph Nodes After Intradermal Injection of ${ }^{18}$ F-FDG. Nucl. Med., 53(9), 1438-1445 (2012). 
9. Thorek, D. L. J., Riedl, C. C., Grimm, J. Clinical Cerenkov Luminescence Imaging of ${ }^{18}$ F-FDG. Nucl. Med., 55(1), 95-98 (2014).

10. Gross, S. et al. Bioluminescence imaging of myeloperoxidase activity in vivo. Nat. Med. 15(4), 455-461 (2009).

11. Lee, J.-J., White, A. G., Rice, D. R., Smith, B. D. In vivo imaging using polymeric nanoparticles stained with near-infrared chemiluminescent and fluorescent squaraine catenane endoperoxide. Chem. Commun., 49(29), 3016-3018 (2013).

12. Lee, D. et al. In vivo imaging of hydrogen peroxide with chemiluminescent nanoparticles. Nat. Mater. 6(10), 765-769 (2007).

13. Baumes, J. M. et al. Storable, thermally activated, near-infrared chemiluminescent dyes and dye-stained microparticles for optical imaging. Nat. Chem. 2(12), 1025-1030 (2010).

14. Siraj, N. et al. Fluorescence, Phosphorescence, and Chemiluminescence. Anal. Chem. 88(1), 170-202 (2016).

15. Hercules, D. M., Lytle, F. E. Chemiluminescence from Reduction Reactions. Am. Chem. Soc., 88(20), 4745-4746 (1966).

16. Kerr, E. Annihilation electrogenerated chemiluminescence of mixed metal chelates in solution: modulating emission colour by manipulating the energetics. Chem. Sci., 6, 472-479 (2015).

17. Montalti, M., Credi, A., Prodi, L., Gandolfi, M. T. Handbook of Photochemistry 3rd Ed. CRC Press Taylor \& Francis Group, Boca Raton, FL, USA., CRC press, p. pp. 379-404. (2006).

18. Gage, G. J., Kipke, D. R., Shain, W. Whole Animal Perfusion Fixation for Rhodents. J. Vis. Exp., 65, e3564 (2012).

19. Büchel, G.E. et al. Near-infrared intraoperative chemiluminescent imaging. ChemMedChem. (2016).

20. Ntziachristos, V., Ripoll, J., Wang, L. V., Weissleder, R. Looking and Listening to Light: the Evolution of Whole-Body Photonic Imaging. Nat. Biotechnol., 23, 313-320 (2005).

21. Koch, J. H., Gyarfas, E. C., Dwyer, F. P. Biological Activity of Complex lons Mechanism of Inhibition of Acetylcholinesterase. Austral. J. Biol. Sci., 9(3), 371-381 (1956).

22. Juris, A., Balzani, V., Barigelletti, F., Campagna, S., Belser, P., Zelewsky, A. V. Ru(II) polypyridine complexes: photophysics, photochemistry, electrochemistry, and chemiluminescence. Coord. Chem. Rev., 84, 85-277 (1988).

23. Knoll, J. D., Turro, C. Control and utilization of ruthenium and rhodium metal complex excited states for photoactivated cancer therapy. Coord. Chem. Rev., 282, 110-126 (2015).

24. Haley, T. J. Pharmacology and toxicology of the rare earth elements. J. Pharm. Sci., 54(5), 663-670 (1965).

25. Siekierski, S., Mioduski, T., Salomon, M. IUPAC Commission on Solubility Data. Solubility Data Series. Vol 13. Scandium, Yttrium, Lanthanum, and Lanthanide Nitrates., Pergamon Press, (1983).

26. Reiner, T., Jantke, D., Marziale, A. N., Raba, A., Eppinger, J. Metal-Conjugated Affinity Labels: A New Concept to Create Enantioselective Artificial Metalloenzymes. ChemistryOpen., 2, 50-54 (2013).

27. Zanarini, S., et al. Synthesis and Electrochemiluminescence of a Ru(bpy $)_{3}$-Labeled Coupling Adduct Produced on a Self-Assembled Monolayer. J. Phys. Chem. C., 112(8), 2949-2957 (2008).

28. Liu, R., Lv, Y., Hou, X., Yang, L., Mester, Z. Protein Quantitation Using Ru-NHS Ester Tagging and Isotope Dilution High-Pressure Liquid Chromatography-Inductively Coupled Plasma Mass Spectrometry Determination. Anal. Chem., 84(6), 2769-2775 (2012).

29. Jantke, D. et al. Synthetic strategies for efficient conjugation of organometallic complexes with pendant protein reactive markers. $J$. Organomet. Chem., 744, 82-91 (2013).

30. Aoki, Y. et al. An experimental xenograft mouse model of diffuse pontine glioma designed for therapeutic testing. J Neurooncol., 108(1), 29-35 (2012).

31. Forster, R. J., Bertoncello, P., Keyes, T. E. Electrogenerated Chemiluminescence. Annual Rev. Anal. Chem., 2, 359-385 (2009).

32. Connell, T. U., James, J. L., White, A. R., Donnelly, P. S. Protein Labelling with Versatile Phosphorescent Metal Complexes for Live Cell Luminescence Imaging. Chem. Eur. J., 21(40), 14146-14155 (2015).

33. Zhou, X. et al. Synthesis, labeling and bioanalytical applications of a tris(2,2'-bipyridyl)ruthenium(II)-based electrochemiluminescence probe. Nat. Protoc., 9(5), 1146-1159 (2014).

34. Bœuf, G. et al. Encapsulated Ruthenium(II) Complexes in Biocompatible Poly(d,I-lactide-co-glycolide) Nanoparticles for Application in Photodynamic Therapy. ChemPlusChem., 79(1), 171-180 (2014).

35. Loizidou, M., Seifalian, A. M. Nanotechnology and its applications in surgery. Brit. J. Surgery., 97(4), 463-465 (2010).

36. Barry, N. P. E., Sadler, P. J. Challenges for Metals in Medicine: How Nanotechnology May Help To Shape the Future. ACS Nano., 7, 5654-5659 (2013).

37. Hasan, K., Bansal, A. K., Samuel, I. D. W., Roldán-Carmona, C., Bolink, H. J., Zysman-Colman, E. Tuning the Emission of Cationic Iridium (III) Complexes Towards the Red Through Methoxy Substitution of the Cyclometalating Ligand. Nat.Sci. Rep., 5, 1-15 (2015).

38. Truong, J. et al. Chemiluminescence detection with water-soluble iridium(III) complexes containing a sulfonate-functionalised ancillary ligand. Analyst., 139 (22), 6028-6035 (2014). 